\title{
Ability for a model to predict crop production variability at the regional scale: an evaluation for sugar beet
}

\author{
Marie LAUNAY* ${ }^{\mathrm{a} *}$ Martine GUÉRIF \\ ${ }^{a}$ Unité Climat-Sol-Environnement, INRA Avignon, Domaine St-Paul, Site Agroparc, 84914 Avignon Cedex 9, France
}

(Received 22 January 2002; revised 24 April 2002; accepted 21 May 2002)

\begin{abstract}
The spatial application of crop models for the prediction of plot yields on a regional scale has specific constraints. Firstly, it supposes accurate input into the model from sources concerning the spatial variability of crop performance. Furthermore, it is necessary for the model to be suitable for simulating interactions between the environment, agricultural practices and the crop which explain this variability. The aim of this article is to evaluate a sugar beet growth model, SUCROS, in terms of its ability to predict the spatial variability of yields on the scale of a beet-producing region. The model was adjusted to the agronomic context of northern France by taking into account the effects of moisture stress on leaf senescence and on the partitioning of assimilates. This modification reduced by more than a half the error of LAI and storage organ dry weight estimates. The modified model was then tested on thirty four plots of two beet production region, and we were able to demonstrate that its performance was closely linked to the accuracy of input variables concerning the climate and soil water properties of each plot.
\end{abstract}

spatial variability / crop model / yield forecasting / model evaluation / sugar beet

Résumé - Une étude de l'aptitude d'un modèle à reproduire la variabilité spatiale de l'état de cultures : cas de la betterave à sucre à l'échelle d'un bassin sucrier du nord de la France. L'utilisation spatialisée des modèles de culture pour prédire les rendements parcellaires à l'échelle régionale implique des contraintes spécifiques. Tout d'abord cela suppose de renseigner correctement les modèles en entrée sur les sources de variabilité spatiale de l'état des cultures. De plus, cela nécessite que les modèles soient aptes à reproduire les interactions entre le milieu, l'itinéraire technique et le peuplement végétal, qui expliquent cette variabilité. L'objectif de cet article est d'évaluer un modèle de croissance de la betterave sucrière, SUCROS, sur sa capacité à prédire la variabilité spatiale des rendements à l'échelle d'un bassin sucrier. Le modèle a été adapté au contexte agronomique du nord de la France par la prise en compte des effets du stress hydrique sur la sénescence et l'allocation des assimilats. Cette modification a réduit de plus de moitié l'erreur d'estimation du LAI et de la matière sèche du pivot. Le modèle modifié a ensuite été testé sur trente-quatre parcelles de deux bassins sucriers, et nous avons montré que ses performances étaient fortement liées à la précision avec laquelle étaient renseignées les variables climatiques et les propriétés hydriques des sols de chaque parcelle.

variabilité spatiale / modèle de croissance / prévision des rendements / évaluation de modèle / betterave à sucre

\section{INTRODUCTION}

The sugar industry requires tools which will predict plot yields on the scale of its supply regions so as to minimise production costs. In contrast, sugar beet growers and technical organisations are more interested in real-time diagnostic tools, which will allow them to adjust inputs to the sugar beet as a crop function of its status. Crop growth models developed by research institutions can be used spatially [1, 24] to supply both a diagnosis of crop status and a forecast of plot yields on the scale of a production region. Spatial variation in the status of crops and yields within a region can be explained by the diversity of environmental factors and cropping systems [16]. Environmental status depends on the type of soil, climate, management (tillage, irrigation, fertilisation, etc.). Cropping systems include all technical methods implemented on plots treated in an identical fashion [21]. Each cropping system can be defined in terms of the type of crops and their sequence in the rotation, and the management applied to these different crops [21]. The structure of the model (as defined by Passioura [19]) used to forecast and diagnose spatial variabilities in crop status must therefore correctly reproduce interactions between the environment, management and the crop. Furthermore, the input variables and model parameters

Communicated by Gérard Guyot (Avignon, France) 
characterising variations in the environment and management must be accurate at the plot level.

The SUCROS crop model [23], developped by the Wageningen Agricultural University and the DLO-Research Institute for Agrobiology and Soil Fertility (AB-DLO), which simulates the biomass production of sugar beet from emergence to harvest on a daily basis, was tested with regard to the forecasting and diagnosis of crop status at the plot level in two production regions in northern France. The first objective of this article was to adapt SUCROS to the cropping context of northern France, where moisture stress may be more frequent and severe than in the Netherlands. We aimed to introduce more effects of moisture stress on the growth and development of the crop, and then to calibrate the new functions thus created. The second objective was to evaluate SUCROS on the scale of two production regions by estimating the yields of thirty four plots sampled in these two regions, with a special focus on its sensitivity to the accuracy of input variables of soil and climate.

\section{ADAPTATION OF THE SUCROS MODEL TO THE REGIONAL CONTEXT}

\subsection{Presentation of the regional agronomic context}

Among the factors that explain the spatial variability in sugar beet yields in northern France, the results of the crop establishment phase, and the summer moisture stress conditions have an important weight.

Over the past fifteen years, growers have brought forward the sowing dates so as to improve the sugar beet cropping cycle with respect to the available solar radiation $[10,20]$. By advancing the sowing date the risks of problematic establishment increase: sowing conditions may generally be less favourable and lead to mechanical obstacles for the emergence of seedlings, such as soil aggregates created by seedbed preparation in wet conditions, or a crust formed by rain after sowing. According to Boiffin et al. [2], these unfavourable conditions may:

1. prolong the period between sowing and emergence (the temperature sum required for emergence may increase from 70 to $200{ }^{\circ} \mathrm{C} \cdot \mathrm{d}$ at base temperature of $3{ }^{\circ} \mathrm{C}$ );

2. and reduce the percentage of emerging plants (from $95 \%$ to $50 \%$ ) and the size of seedlings, which in turn is correlated with the elapsed time between sowing and emergence.

Durr et al. [9] showed that variability in the results of the establishment phase (thermal time from sowing to emergence, number of plants emerged, weight of the plants) could explain as much as $20 \%$ of variation in final yield.

Furthermore, summer periods of limiting soil water conditions, corresponding to hot periods when the evapotranspiration demand is high and soil water reserve insufficient, are common in northern France and generally in Europe [13]. They result in reduced growth, by limiting the interception of solar radiation by leaves and the efficiency of photosynthesis [6]. The interception of solar radiation is impaired because of an increase in the leaf senescence rate [17] and a reduction in the partitioning of assimilates for leaf production $[18,26]$.

\subsection{Initial state of the SUCROS model}

In the SUCROS model [23], the basis for calculating dry matter production is the gross $\mathrm{CO}_{2}$ assimilation rate of the canopy. This rate depends on the absorbed solar radiation, which is a function of incoming radiation and crop leaf area. From the absorbed radiation and the photosynthetic characteristics of single leaves (including crop age and air temperature dependence), the daily rate of $\mathrm{CO}_{2}$ assimilation is calculated. Part of the carbohydrate $\left(\mathrm{CH}_{2} \mathrm{O}\right)$ produced is respired for maintenance processes, while the other part is transformed into biomass, with a growth energy cost dependent upon the plant organ considered. Partitioning of the biomass to the different organs varies as a function of the phenological age of the plant [22].

The model simulates crop growth from emergence (expressed as the temperature sum at base temperature $3{ }^{\circ} \mathrm{C}$ from sowing) until the plants become competitive for light $(\mathrm{LAI}=0.75)$. During this period, the leaf area index, LAI, is described as an exponential function (Eq. (1)) of the temperature sum since sowing (ST), and depends on four parameters:

$$
\mathrm{LAI}=\mathrm{LAO} \times \mathrm{NPL} \times \exp ^{(\mathrm{RGRL} \times(\mathrm{ST}-\mathrm{TMSEM}))}
$$

(1) leaf surface area per plant at emergence LA0 $\left(\mathrm{m}^{2} \cdot\right.$ plant $\left.^{-1}\right)$; (2) number of plants per $\mathrm{m}^{2} \mathrm{NPL}$;

(3) relative growth rate of leaf surface RGRL $\left(\mathrm{m}^{2}\right.$ of new leaves per $\mathrm{m}^{2}$ of existing leaves per ${ }^{\circ} \mathrm{C} \cdot \mathrm{d}$ );

(4) temperature sum necessary for emergence TMSEM $\left({ }^{\circ} \mathrm{C} \cdot \mathrm{d}\right.$, base $3{ }^{\circ} \mathrm{C}$ ).

Default values for these parameters are $0.98 \mathrm{~cm}^{2} \cdot$ plant $^{-1}$ for LA0, 11.1 plants $\cdot \mathrm{m}^{-2}$ for NPL, $0.156 \mathrm{~m}^{2} \cdot \mathrm{m}^{-2} \cdot\left({ }^{\circ} \mathrm{C} \cdot \mathrm{d}\right)^{-1}$ for RGRL and $120{ }^{\circ} \mathrm{C} \cdot \mathrm{d}$ for TMSEM. The RGRL parameter may be considered as constant [8], but the other parameters must be accurately determined for each cropping situation.

SUCROS describes yield under limiting soil water conditions [25], but takes no account for other limiting factors such as nitrogen availability, competition with weeds or the presence of parasites or diseases. The soil is described as a multilayer reservoir, each layer being characterised by its thickness and its water retention properties (water contents for specific levels of water potential in the soil). Capillary rise is not simulated. A module for water management in the soil and the plant calculates the evaporation from the soil and the transpiration from the plant on a daily basis. The actual transpiration rate is calculated from the atmospheric demand for water, and the water available in each soil layer. A daily moisture stress factor of between 0 and 1 is calculated as the ratio of actual to potential transpiration rate. This factor is applied to the daily total gross $\mathrm{CO}_{2}$ assimilation rate to reduce photosynthesis [23]. A second moisture stress factor intervenes in the partitioning of assimilates between functional roots and the rest of the plant, favouring partition 


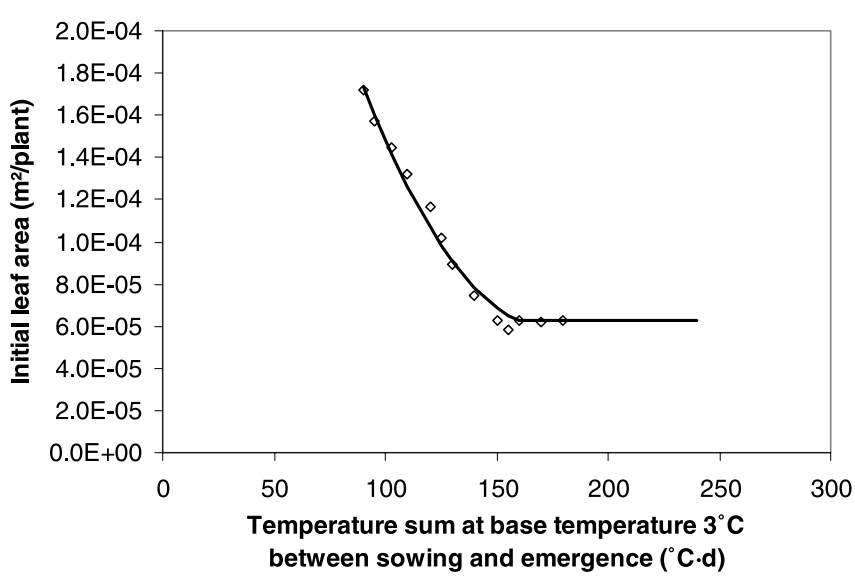

Figure 1. Regression established between initial leaf area per plant and temperature sum at base $3{ }^{\circ} \mathrm{C}$ between sowing and emergence $(\diamond$ initial leaf surface per plant, - regression).

towards functional roots in the event of major moisture stress [4].

\subsection{Modifications introduced into the SUCROS model}

\subsubsection{Calculation of the initial leaf surface area per plant as a function of the time between sowing and emergence}

The crop establishment phase is a determining factor in terms of final yield [9]. Obviously, this result may vary and be difficult to quantify at the scale of a sugar beet production region. It is therefore particularly important to reduce the number of parameters which enable its description to a minimum. With this in mind, we have introduced a relationship between the temperature sum between sowing and emergence TMSEM and the initial leaf surface area parameter LA0, because it is difficult to estimate the latter for every field on a regional scale. We used the experimental findings of Boiffin et al. [2] to obtain a quadratic regression (Eq. (2)) between LA0 and TMSEM (Fig. 1) which we have introduced into the model:

$$
\begin{gathered}
\mathrm{LAO}=\left(55-0.56 \times \mathrm{TMSEM}+0.0016 \times \mathrm{TMSEM}^{2}\right) \times 10^{-5} \\
\left(\mathrm{R}^{2}=0.99\right) .
\end{gathered}
$$

\subsubsection{Modifications to improve the allowance for moisture stress}

Our aim was limited to adapting the model to produce yield estimations on the scale of a sugar beet production region during 1995. The SUCROS model was adapted and calibrated using data acquired during two trials conducted at Clermont in 1994 [12] and at Mons in 1995 [5], in the Picardy region. For both years, drought conditions occured around $1200^{\circ} \mathrm{C} \cdot \mathrm{d}$ after emergence. During these trials, the LAI, the biomass of green and dead leaves and the biomass of the storage organ were

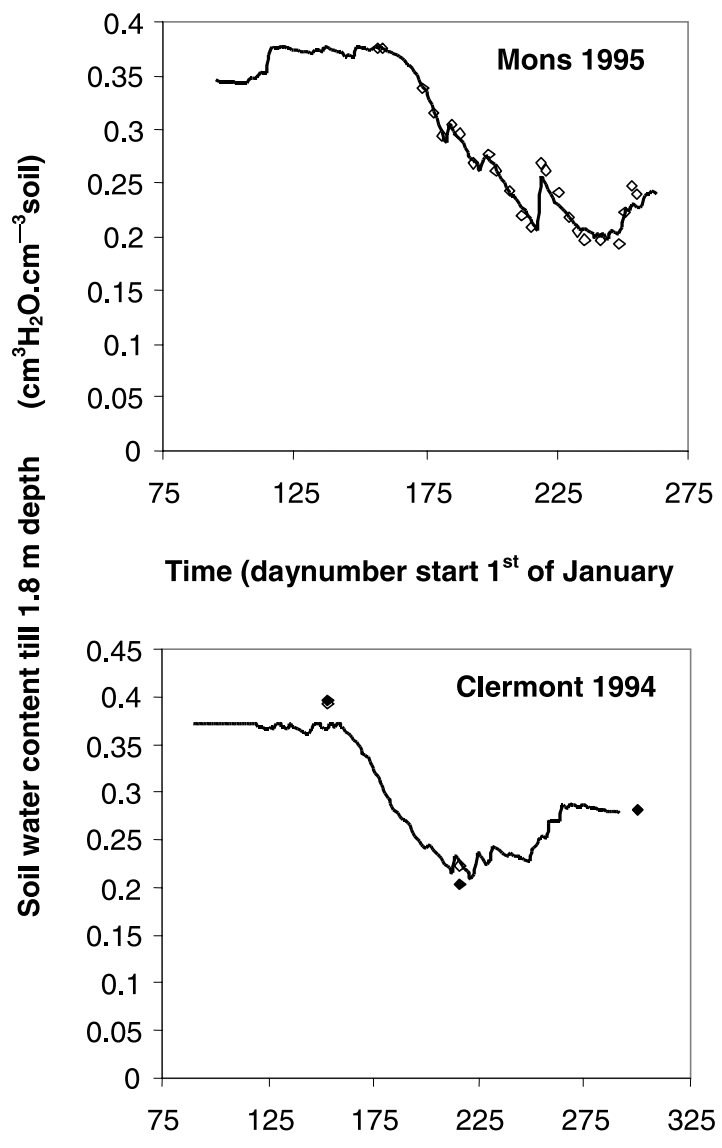

Figure 2. Comparison of integrated soil water contents simulated by SUCROS, with the soil water content measured (a) during the trial in Mons-en-Chaussée in 1995 and (b) during the trial in Clermont Les Fermes in $1994(\diamond \diamond$ observed water content, - simulated water content).

measured at intervals ( 7 to 14 days) during the growing season. The water content of 5 soil layers $(0$ to $180 \mathrm{~cm})$ was measured at intervals of 7 days, using a neutron probe on 4 places in the experimental plot.

Having ensured that the SUCROS water management module was reliable, since the soil water content was accurately simulated (Fig. 2), we observed that the model did not reproduce the LAI behaviour in the event of moisture stress (Fig. 3). Strong reductions of the observed LAI were noticed between days 213 and 228 in Mons, and between days 201 and 214 in Clermont (the moisture stress increased as shown by evolution of the moisture stress factor), followed by regrowth when the stress reduced; on the other hand, during the same period the simulated LAI remains constant.

We then proposed several modifications based on studies which demonstrate the effect of moisture stress on leaf senescence rate and on the partitioning of assimilates between above ground and storage organ parts. As a quantification of the moisture stress, we considered the first moisture stress factor of the model (ratio of actual to potential transpiration rate). Firstly, Milford et al. [17] demonstrated that a period of 


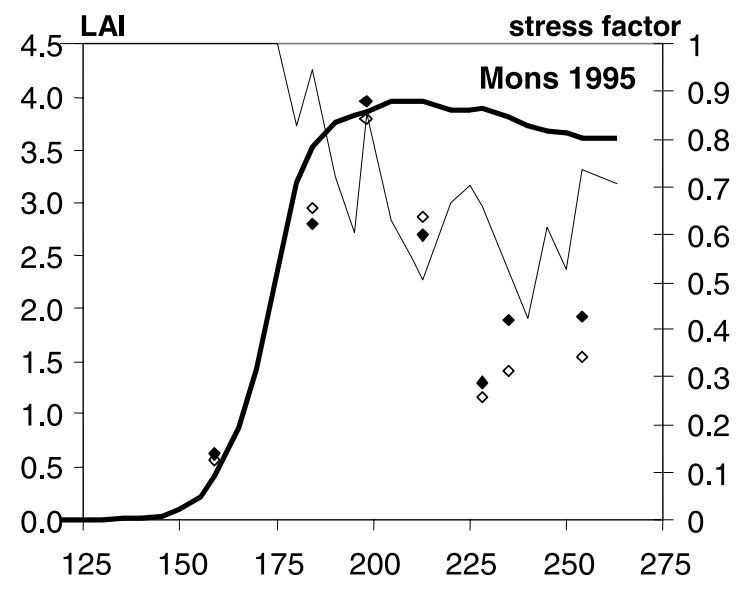

Time (daynumber start $1^{\text {st }}$ of January)

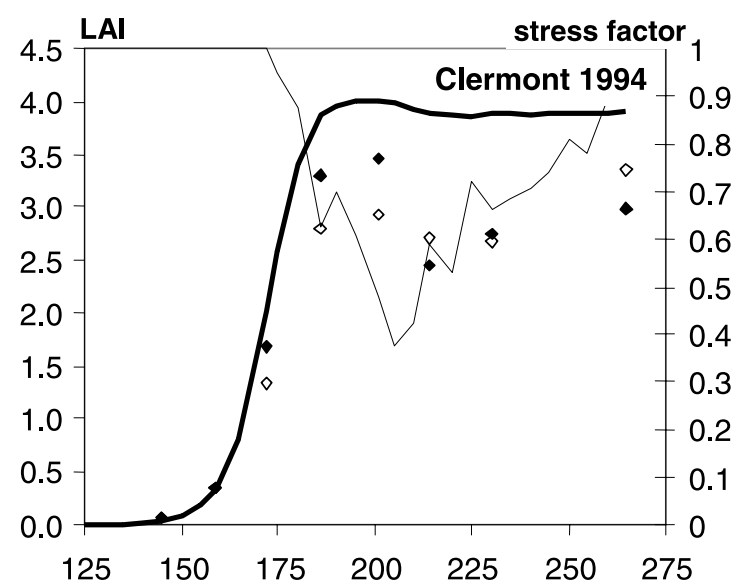

Figure 3. Simulations of the LAI by the initial SUCROS model during the trials in Mons-en-Chaussée in 1995 and Clermont Les Fermes in 1994. Comparison with measured LAI $(\diamond$ observed LAI block I, observed LAI block II, - simulated LAI, --- moisture stress factor).

moisture stress caused an increase in the leaf senescence rate, and that leaf senescence rate was temporarily reduced (and cancelled) when the stress was relieved (and stopped). We therefore introduced into the model a relationship between the rate of leaf senescence and the moisture stress factor considered in terms of both its level and its direction (decreasing or increasing). Secondly, Werker et al. [26] demonstrated that the proportion of dry matter allocated to above ground organs diminished more rapidly as the moisture stress increased. In addition, although moisture stress hinders leaf growth, the relief of stress is accompanied by a marked retriggering of leaf growth [5, 7]. The modification of assimilate partitioning at the relief of stress didn't explain such a restarting of above ground organ growth. Dry matter translocation from the storage organ towards the above ground organs must be considered to explain this resumption of growth. We therefore sought to introduce the effect of magnitude of moisture stress and whether it was increasing or decreasing into the model, with respect to the partitioning of assimilates between above ground and storage organs, and to the translocation of dry matter from the storage organ to above ground organs.

In order to describe these relationships, we used the measurements obtained during the experiments in Mons and Clermont.

In a first instance, we calculated the observed leaf senescence rate between two measurement dates as the ratio of the change in dead leaf mass to the mean green leaf mass. We established the ratio between this observed leaf senescence rate and the simulated leaf senescence rate under potential growth conditions, as given by SUCROS. This ratio was linked with the mean moisture stress factor between the two measurement dates, calculated from daily values simulated by SUCROS (Fig. 4). The ratio of leaf senescence rate depended upon the amount of stress, but also on its direction (Fig. 4a): when moisture stress increased, the ratio rapidly reached a value close to 4 , and when the stress diminished, the observed leaf senescence rate fell rapidly to reach the senescence rate simulated for potential growth conditions, even before the stress had completely disappeared. The rate of evolution of the stress during a period between 2 measurements was characterised by the sum of the daily variations of the moisture stress factor. When comparing this rate to the ratio between senescence rates (Fig. 4b), it was obvious that the observed senescence rate could become less than the senescence rate under potential growth conditions when the moisture stress factor fell markedly: this is coherent with the observations made by Milford et al. [17]. The measurements shown in Figure $4 \mathrm{~b}$ enabled us to establish a regression between the ratio of senescence rate, the mean moisture stress factor and the sum of daily variations in this factor between two measurement points, with a coefficient of determination $\mathrm{R}^{2}$ of 0.84 (Eq. (3)).

$$
\begin{aligned}
& \frac{R D R_{j}}{R D R S T_{j}}=3.5-1.8 \times \overline{\left.D F_{(j-5, j-1}\right)}-9.6 \\
& \times \quad \sum_{i=j-5}^{i=j-1}\left(D F_{i}-D F_{i-1}\right)+7.0 \\
& \times D F_{(j-5, j-1)} \times \sum_{i=j-5}^{i=j-1}\left(D F_{i}-D F_{i-1}\right)
\end{aligned}
$$

where $R_{D R}$ is the observed senescence rate at day $j, R_{D R S T}$ the simulated senescence rate under potential growth conditions and DF the moisture stress factor (actual transpiration/ potential transpiration).

Secondly, we modelled the effect of moisture stress on the partitioning and translocation of assimilates between the storage organ and the above ground organs. We hypothesised that below a certain threshold of moisture stress THR1, when this stress is increasing, all assimilates were directed towards the storage organ, to the loss of above ground organs. We also supposed that above THR1, and below a threshold THR2, in the case where this stress is decreasing, a fraction of dry 


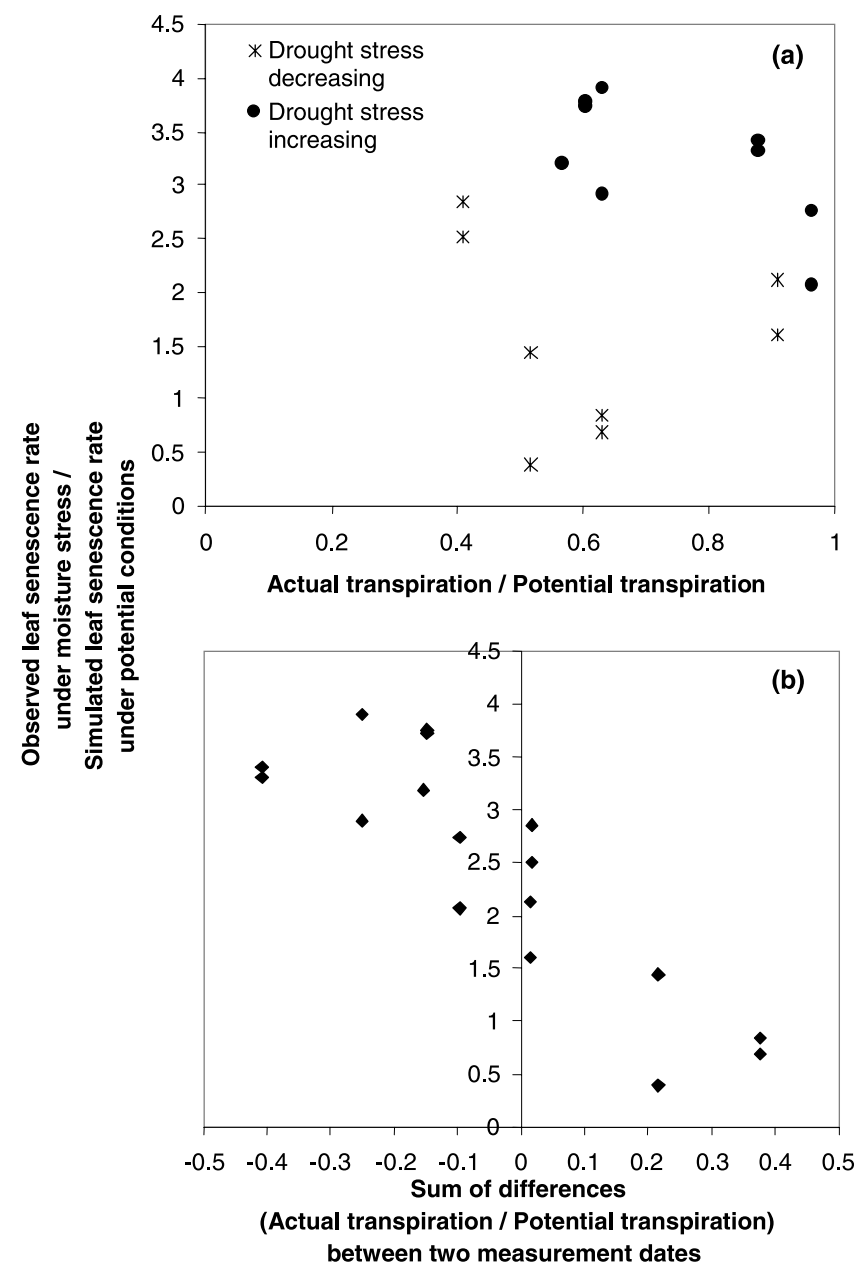

Figure 4. Ratio between real leaf death rate observed and leaf death rate under potential growth conditions (a) as a function of the mean moisture stress factor (mean ratio between real transpiration and potential transpiration between two measuring points), and (b) as a function of the sum of daily variations in the moisture stress factor between two measurements, during the two trials in Mons-enChaussée and Clermont Les Fermes.

matter, PARLSO, was, each day taken from the storage organ and redirected towards the above ground organs. We sought to determine the values for the PARLSO, THR1 and THR2 parameters which would minimise the sum of relative root mean squared error (RRMSE) of prediction of LAI and storage organ weight (collected during these two experiments). The values given to these parameters ranged from 0.5 to 0.9 for THR1 and THR2 (with a step of 0.1 ), and from 0.002 to 0.01 for PARLSO (with a step of 0.001). When THR1 $=$ THR2, there is no translocation. The RRMSE was minimal for the parameter set $(\mathrm{PARLSO}=0.007, \mathrm{THR} 1=0.7$, THR2 $=0.9$ ). These values were therefore introduced into the model.

Figure 5 compares simulations of the LAI, the dry mass of the storage organ and the dry mass of dead leaves in the initial and modified SUCROS models during the two field experiments used for calibration. Variations in the LAI, storage organ weight and senescent leaf weight throughout growth were better simulated by the modified model. The root mean squared errors (RMSE) of LAI, senescent biomass and storage organ dry weight were halved reduced (Tab. I).

It was only possible to determine the approximate effect of moisture stress on leaf senescence, and this effect was integrated on a daily basis into the model, while it was characterised over periods of approximately ten days using measurements. The partitioning and translocation of dry matter between the above ground and storage organs as a function of moisture stress were also calibrated with a small number of measurements and climatic situations.

\section{EVALUATION OF THE MODEL ON THE SCALE OF TWO SUGAR BEET PRODUCTION REGIONS}

\subsection{Data}

\subsubsection{Plant community}

During 1995, thirty four fields were sampled within two sugar beet production regions of northern France, one supplying the Eppeville sugar refinery and the other the Marle refinery (Fig. 6). The area of each region was approximately $20 \times$ $30 \mathrm{~km}$. These fields were chosen to represent a wide range of establishment conditions and soil textures. Yields were measured on a $2-4$ hectare zone, within each field. These harvested zones will hereinafter be referred to as «plots». For each of these plots, the sowing date, emergence date, emerging density, were measured on 10 plots of $6 \times 12 \mathrm{~m}$ (Fig. 7); harvest date, variety, major cultivation operations and health status of plants during cultivation were also recorded.

Table I. Root mean square errors (RMSE) of LAI, senescent biomass dry weight and storage organ dry weight estimates, on the trials of Mons and Clermont, for the two SUCROS versions (initial and modified).

\begin{tabular}{lcccccc}
\hline \multirow{2}{*}{ RMSE } & \multicolumn{2}{c}{ LAI estimate } & \multicolumn{2}{c}{$\begin{array}{c}\text { Senescent biomass dry weight estimate } \\
\left(\mathrm{kg} \cdot \mathrm{ha}^{-1}\right)\end{array}$} & \multicolumn{2}{c}{$\begin{array}{c}\text { Storage organ dry weight estimate } \\
\left(\mathrm{kg} \cdot \mathrm{ha} \mathrm{l}^{-1}\right)\end{array}$} \\
\cline { 2 - 7 } & initial & modified & initial & modified & initial & modified \\
\hline Mons 1995 & 1.56 & 0.56 & 611 & 410 & 611 & 310 \\
Clermont 1994 & 0.82 & 0.35 & 989 & 583 & 30 \\
\hline
\end{tabular}


(a)
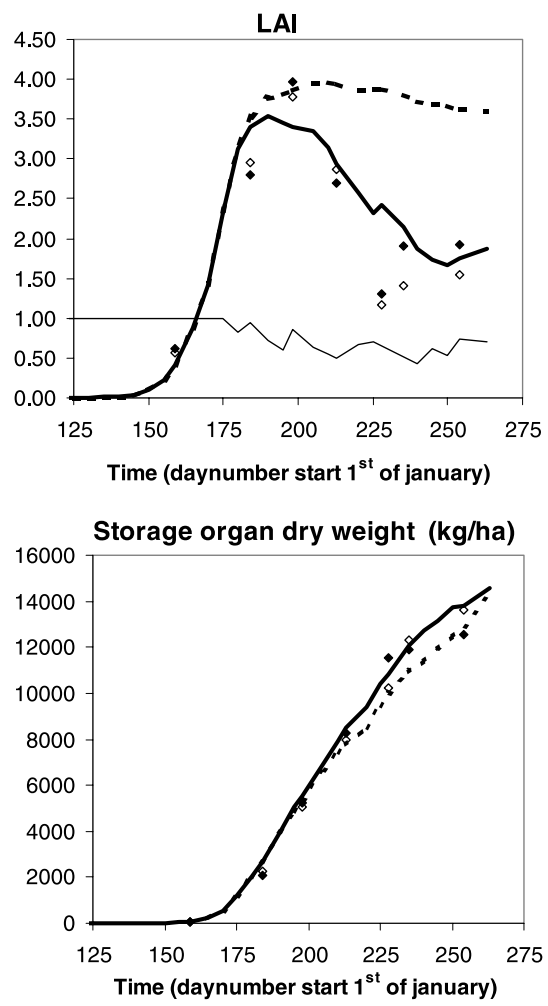

Dead leaves and stems dry weight (kg/ha)

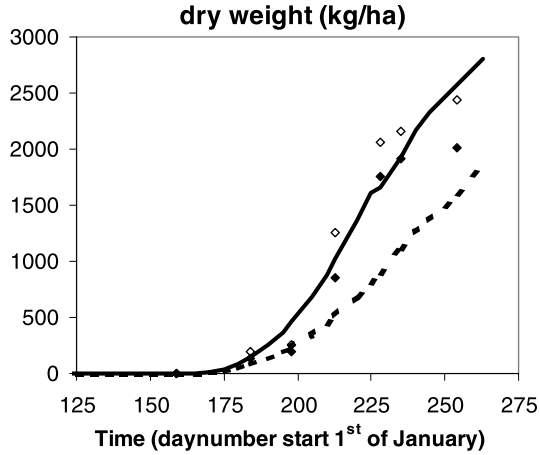

(b)

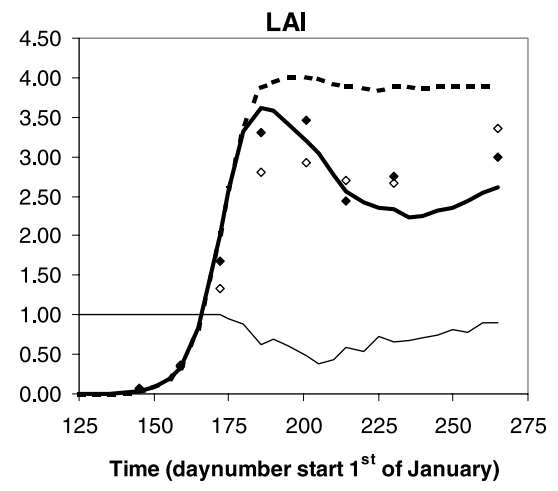

Storage organ dry weight (kg/ha)

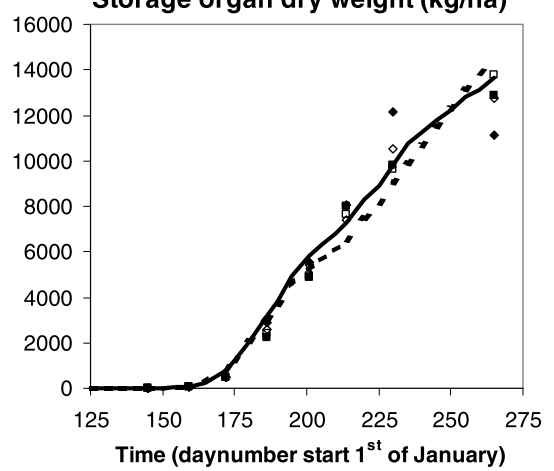

Dead leaves and stems

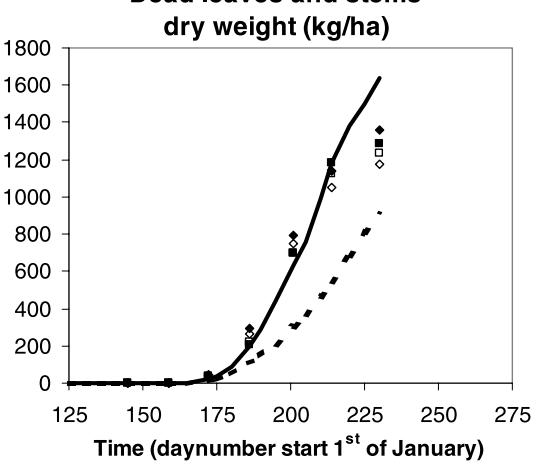

Figure 5. During the trials in Mons in 1995 (a) and Clermont in 1994 (b), LAI, dry matter of storage organs and dead leaves simulated using the initial version of SUCROS and the modified version of SUCROS compared with the LAI, dry matter of storage organs and dead leaves measured $(\diamond \bullet \square$ variables observed in different blocks, ---- variables simulated with initial SUCROS, - variables simulated with modified SUCROS, - drought stress factor).

\subsubsection{Weather}

To characterise the weather of each plot, we used data obtained in 1995 from the network of local weather stations run by Météo France. Plots in the Eppeville region were between 2 and $11 \mathrm{~km}$ from the Fontaine Les Clercs station. The Vervins station is north of the Marle region, while La Selve is south of the Marle region, at least $8 \mathrm{~km}$ from the nearest plot (Fig. 6). Plots in the Marle region were further from weather stations than those in the Eppeville region, some of them $19 \mathrm{~km}$ from the nearest station. Figure 8 describes the climatic features of the 3 weather stations relative to each other, during two critical periods: establishment (01/03-15/06) and mature growth (15/06-30/09). The risks of problematic establishment would be greater on plots with a lower temperature (longer period between sowing and emergence) and higher rainfall (risks of soil crusting on loamy surfaces): this seemed more likely probable for the plots represented by the Vervins weather station (plots to the north of the Marle region). In contrast, at Fontaine Les Clercs or La Selve (plots in the Eppeville region and the south of the Marle region), establishment was more likely to be rapid. During mature growth, moisture demands would be greater at higher temperatures, and moisture stress phenomena could occur if 

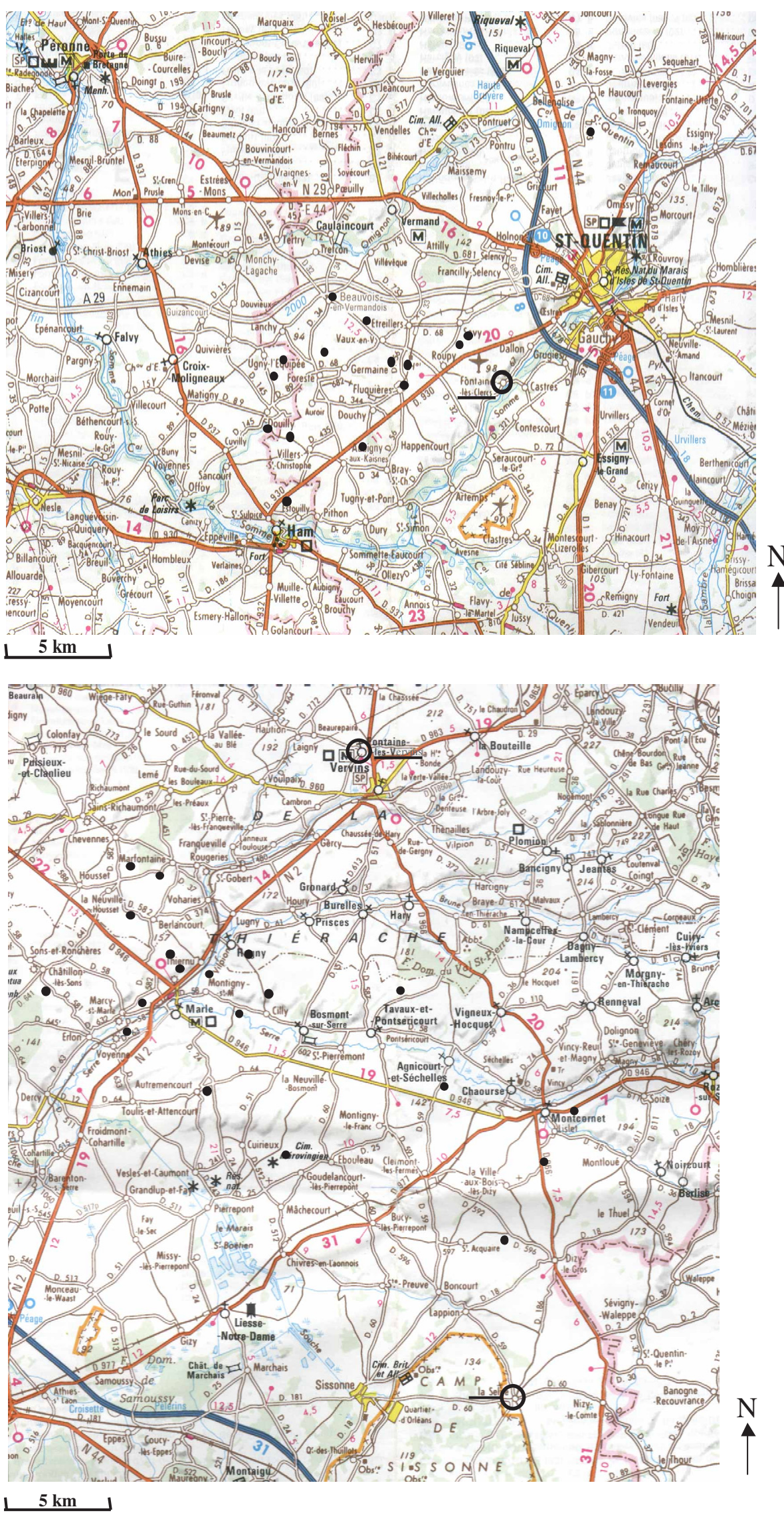

(a)

(b)

Figure 6. Geographical situation of the 34 plots sampled in sugar beet-producing regions supplying the (a) Eppeville and (b) Marle sugar refineries, and the three nearest local weather stations (IGN, top 250, Paris, 1999) (• field, $\bigcirc$ weather station). 
(a)

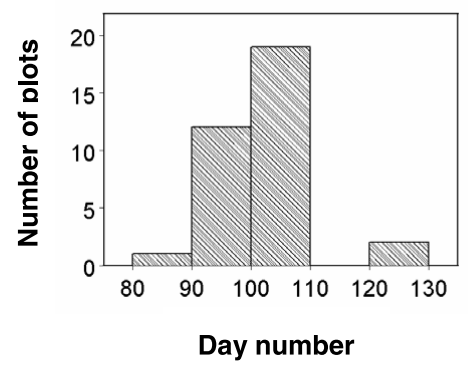

(b)

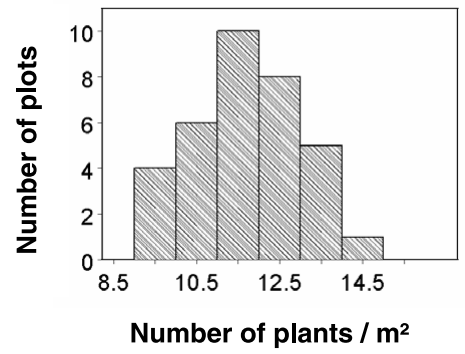

(c)

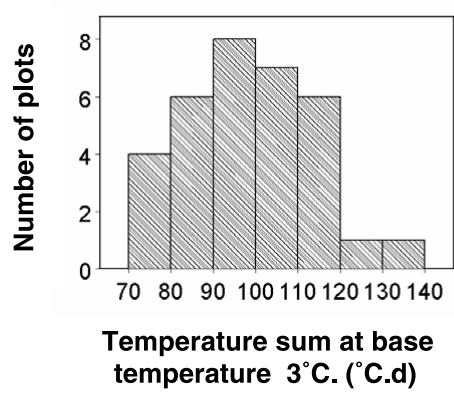

Figure 7. Distribution of variables characteristic of the results of the establishment phase on the 34 sampled plots (a) date of sowing, (b) number of plants emerging, (c) time from sowing to emergence.

there was insufficient rainfall, as at Fontaine Les Clercs and La Selve.

The hillier topography of the Marle region may give rise to greater climatic variations from place to place than at Eppeville, as demonstrated by the differences in temperature and rainfall between the stations at Vervins and La Selve. On the contrary the region around Eppeville is mainly a plateau, probably with less climatic variation.

\subsubsection{Soils}

Soil textures were obtained from the soil map for the Aisne department at the scale 1:10000, which describes the different soil horizons to a depth of $1.2 \mathrm{~m}$. The water retention properties of these soils were deduced from the map using the pedotransfer rules supplied by Jamagne et al. (1977). Data on
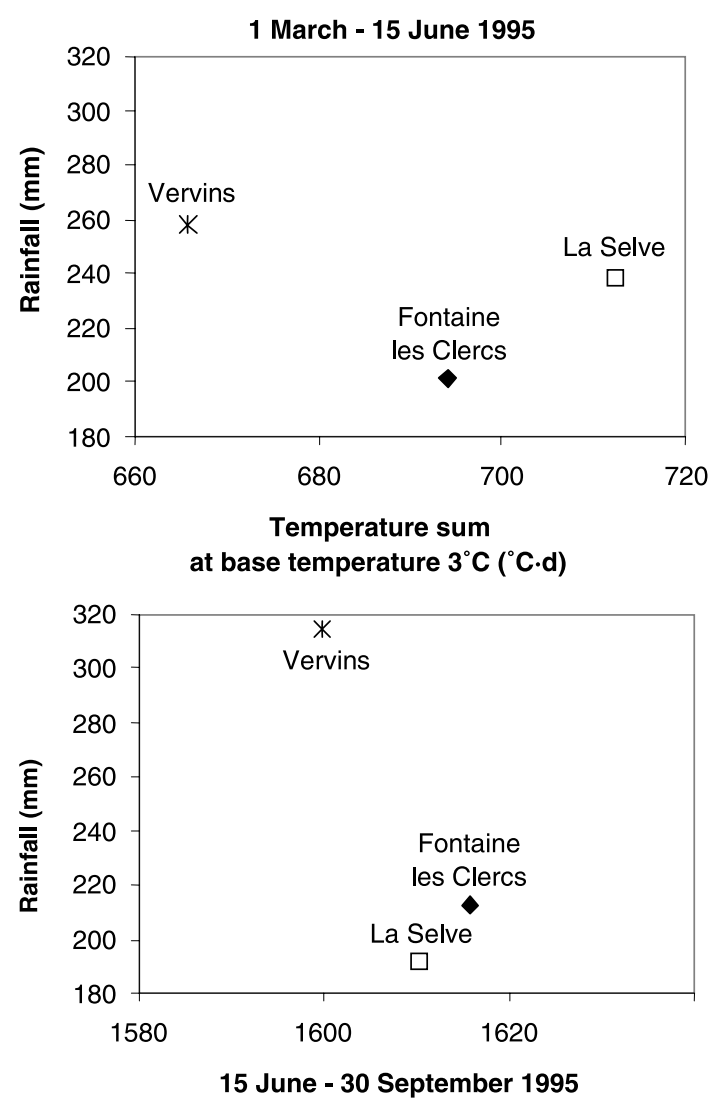

Figure 8. Climatic characteristics of weather stations in the Eppeville ( $\bullet$ ) and Marle ( $\square$ and *) regions: sums of rainfall and temperatures (a) during the early growth period (March 1st to June 15) then (b) during the mature growth period (June 15 to September 30).

only three plots, situated in the Somme department, were not supplied by this map, and these were characterised as a function of their proximity to other plots where accurate details were available, or as a function of observations made in the field. The principal textures encountered were silt loam on clay loam, clay loam and deep silt loam (Tab. II). In the knowledge that the soils in this area are particularly deep, and based on several samples taken from deeper than $1.2 \mathrm{~m}$, we hypothesised that the soil information provided to a depth of $1.2 \mathrm{~m}$ by this map in fact could be extended to a depth of $1.8 \mathrm{~m}$. In the context of this region chalk may be either an impenetrable substratum or a permeable one (Maucorps, personal com.). Without any precise information on the type of chalk present in the plots, we stated that it was a substratum impenetrable by the roots. We shall analyse in the results the consequence of this statement. Soil water reserves were calculated with a range of between $0.05 \mathrm{~cm}^{3} \mathrm{H}_{2} \mathrm{O} \cdot \mathrm{cm}^{-3}$ soil $\cdot \mathrm{m}$ and $0.35 \mathrm{~cm}^{3} \mathrm{H}_{2} \mathrm{O} \cdot \mathrm{cm}^{-3}$ soil $\cdot \mathrm{m}$ for all profiles (Tab. II), on the basis of these two hypotheses:
(a) all soils extend to $1.8 \mathrm{~m}$;
(b) chalk is impenetrable by roots. 
Table II. Surface areas of soil texture types encountered on all plots in the sample and maximum soil water availability in metres per texture type (MSWA) $(\mathrm{MSWA}=($ soil water content at field capacity - soil water content at wilting point $) \times$ soil depth $)$.

\begin{tabular}{|c|c|c|c|c|c|}
\hline & Silt loam on clay loam & Clay loam & Silt loam & Clay loam on silt loam & Other textures \\
\hline$\%$ of total surface & $45 \%$ & $30 \%$ & $12 \%$ & $6 \%$ & $7 \%$ \\
\hline $\operatorname{MSWA}\left(\mathrm{cm}^{3} \mathrm{H}_{2} \mathrm{O} \cdot \mathrm{cm}^{-3}\right.$ soil $\left.\cdot \mathrm{m}\right)$ & 0.17 to 0.34 & 0.06 to 0.35 & 0.32 & 0.33 & 0.05 to 0.33 \\
\hline
\end{tabular}

\subsection{Method}

To take into account intra-plot variability in soil types we divided each plot into sub-plots, on the basis of the contours of the soil map, thus delimiting zones of homogenous soil texture and cultivation techniques: these zones were referred to as "functional units". The simulations were made on each functional unit, and then the plot yield was integrated from yields simulated for the sub-plot.

The model could not be evaluated independently without knowing the effect of the accuracy of climate and soil input variables on yield estimates. To achieve this, we divided the 34 plots in our sample into four groups:

- a first group of plots for which the climate and soil type were considered to be accurately detailed, i.e. they were within the influence area of the nearest weather station and accurate details were available from the soil map;

- a second group of plots where the soil type was accurately detailed, but weather data were inaccurate, i.e. the plots were outside the influence area of the nearest weather station;

- a third group including plots not described by the soil map for the Aisne department, but with well-characterised weather data;

- a final group of plots, with accurately detailed soil and weather information but where more than a quarter of the surface was on a chalk substratum, for which water retention properties are difficult to describe.

We sought to determine the influence area of weather stations as being the maximum distance between plots and stations beyond which it was no longer possible to consider the weather described by the station as being sufficiently representative of that of the plot. As a criterion of representativity we considered the quality of the simulation by SUCROS, with the hypothesis that other error sources in the model would be independent of the weather station proximity. To achieve this, we simulated the yield of each plot in the Eppeville region with the weather data coming from the weather station at Fontaine Les Clercs, and the yield of each plot in the Marle region with the weather data coming from the La Selve station and then that described by the Vervins station. We then examined the relative error of yield estimation per plot as a function of the distance of the plot from the weather station used for simulation. We limited ourselves to the 29 plots described by the soil map, excluding any with a chalky substratum.

We used the first group of plots to evaluate the capacities of the initial and then the modified models to reproduce the spatial variability of yields. The second and third groups of plots enabled us to estimate the error caused by the poor spatial description of input variables characterising the climate and soil. Finally, the last two plots demonstrated the need for

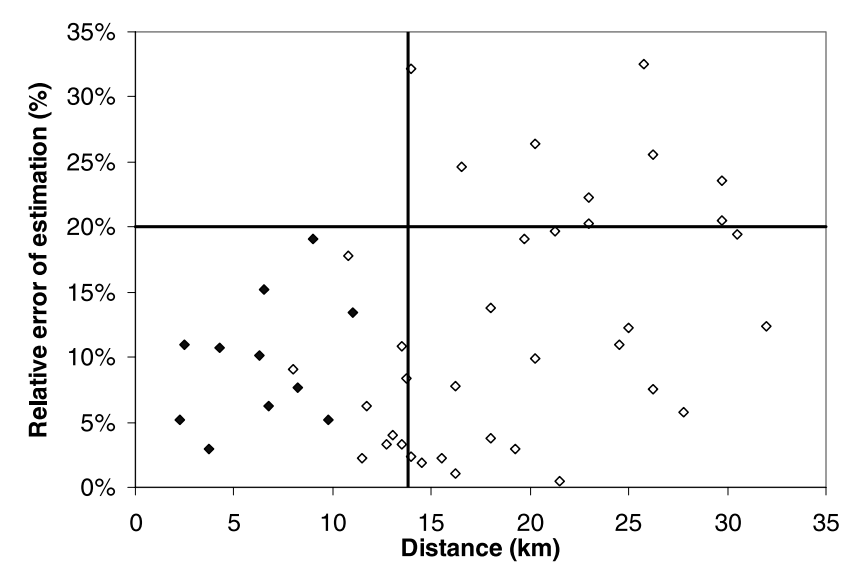

Figure 9. Relative deviations between yields simulated by the modified SUCROS model and yields measured as a function of the distance of plots from weather stations ( $\bullet$ Eppeville region, $\diamond$ Marle region).

improved characterisations of the water retention properties of soils on a chalk substratum.

The evaluation criteria were:

- the efficiency of the model (EF) [15] which measured the improvement in yield estimates provided by the model compared with those obtained using observational data,

$$
E F=1-\left(\sum\left(y_{i}-\hat{y}_{i}\right)^{2}\right) /\left(\sum\left(y_{i}-\bar{y}_{i}\right)^{2}\right)
$$

where $y_{i}$ are the observed values (with a mean of $\bar{y}_{i}$ ) and $\hat{y}_{i}$ the simulated values;

- the root mean squared error (RMSE) and relative root mean squared error (RRMSE) supplying a mean value for the yield estimate error,

$$
R M S E=\sqrt{\frac{1}{n} \sum\left(y_{i}-\hat{y_{i}}\right)^{2}}, \quad R R M S E=\frac{1}{y_{i}} \sqrt{\frac{1}{n} \sum\left(y_{i}-\hat{y_{i}}\right)^{2}}
$$

- the linear regression characteristics (slope, intercept, coefficient of determination $\mathrm{R}^{2}$ ), which indicated the presence or not of an estimation bias and the quality of plotby-plot estimates.

\subsection{Results}

\subsubsection{Definition of the influence area of weather stations}

Figure 9 shows the relative errors of yield estimations for plots as a function of their distance from the weather station. 
Table III. Evaluation criteria for the model depending on the accuracy of climatic and soil moisture property variables of plots.

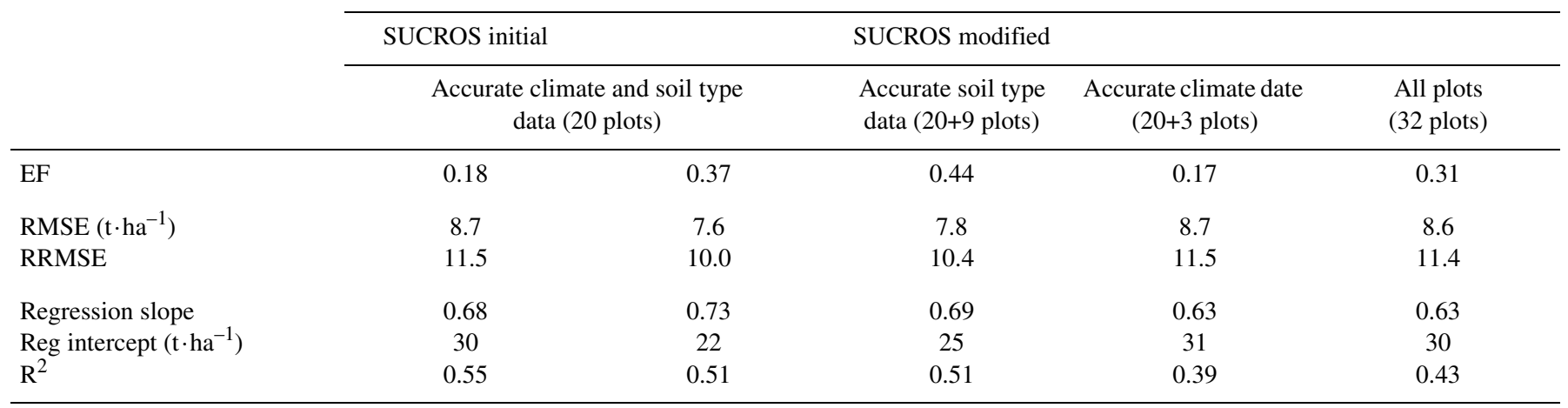

Plots in the Marle region were at much more variable and generally greater distances from weather stations than those in the Eppeville region. For the plots less than $14 \mathrm{~km}$ from the weather station, the root mean square error (RMSE) seems independent from the distance and always less than $20 \%$. We concluded that beyond $14 \mathrm{~km}$, we could not accept the hypothesis that the climate described by the station was representative of that of the plot, if we did not want to have more than $20 \%$ of relative error of yield estimation. This distance served to identify the first group of 20 plots where the climate and soil were considered to be accurately detailed.

\subsubsection{Performance of the model regarding accurately detailed plots}

In the first group of 20 plots, each plot in the Eppeville region was attributed the weather prevailing at the Fontaine Les Clercs station, and each plot in the Marle region was attributed the weather prevailing at the La Selve or Vervins stations, whichever was closer. We compared the obtained results using the initial and modified SUCROS models (Tab. III). Model efficiency was improved when moisture stress was taken into account. The root mean square error (RMSE) of yield prediction was reduced from 8.7 ton/ha to 7.6 ton/ha and the RRMSE from $11.5 \%$ to $10.0 \%$. The linear regression between observed and simulated yields demonstrated an improvement for the modified model as compared to the original one (Figs. 10a and b): the regression slope was no longer significantly different from 1.0 (Student's $\mathrm{T}$ test, 0.05 significance level), which would be the ideal situation, and the regression intercept was reduced. The estimation bias (overestimation of low yields) was thus reduced and the yield range was better reflected. In contrast, the coefficient of determination was slightly weaker in the case of the modified model.

\subsubsection{Performance of the model on inaccurately detailed plots}

To the first group of plots, we added data from the second group of 9 plots (those more than $14 \mathrm{~km}$ from the nearest weather station), then we added the third group of three plots lying outside the soil map. Similarly, we compared the simulated and observed yields of these 29 plots, then on the 23 plots and finally on all 32 plots (Tab. III). Model
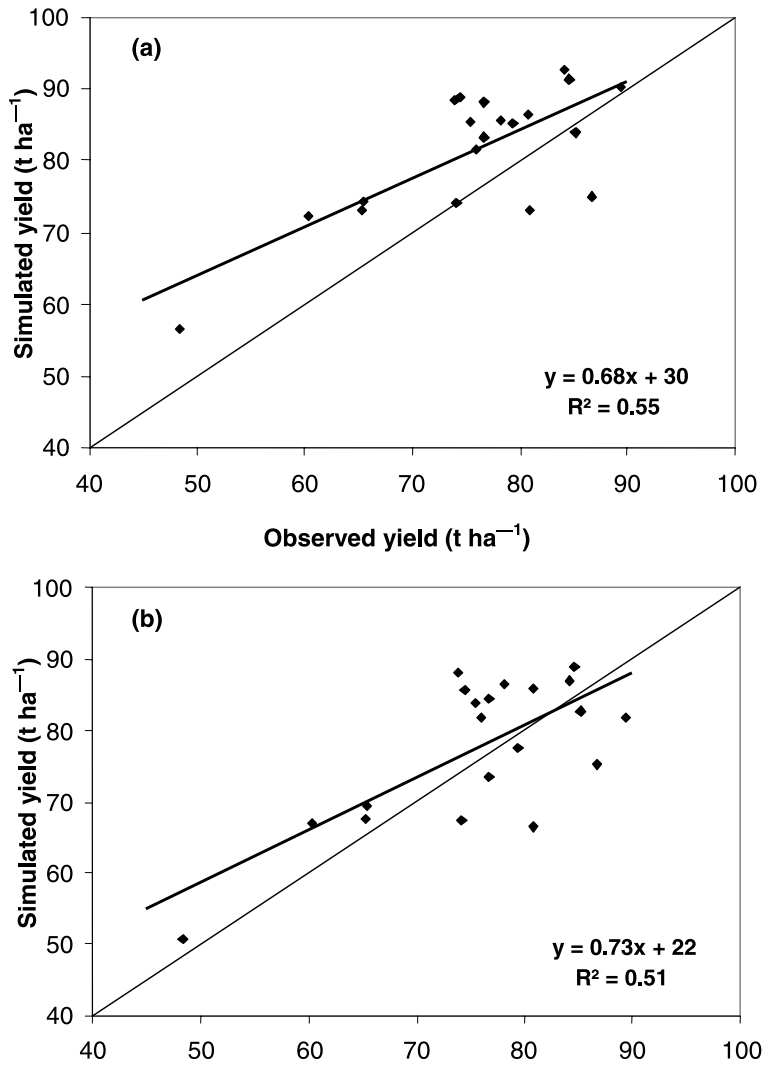

Figure 10. Yields simulated (a) by the initial SUCROS model, and (b) by the modified SUCROS model, as a function of yields observed for the 20 plots with accurately detailed information on climate and soil type (- regression, - line $1: 1, \mathrm{n}=20$ ).

performance was hardly affected by the addition of plots with a poorly characterised climate (Fig. 11). Only one plot out of the nine in the second group fell outside the scatter diagram, corresponding to a considerable overestimation of yield by the model. In the third group where the three plots falling outside the soil map were added, the results in terms of RMSE were worse $(8.7 \mathrm{t} / \mathrm{ha})$. However it is difficult to conclude that bad soil characterization has a serious deleterious impact on yield estimate, because this result was based on so few plots. 


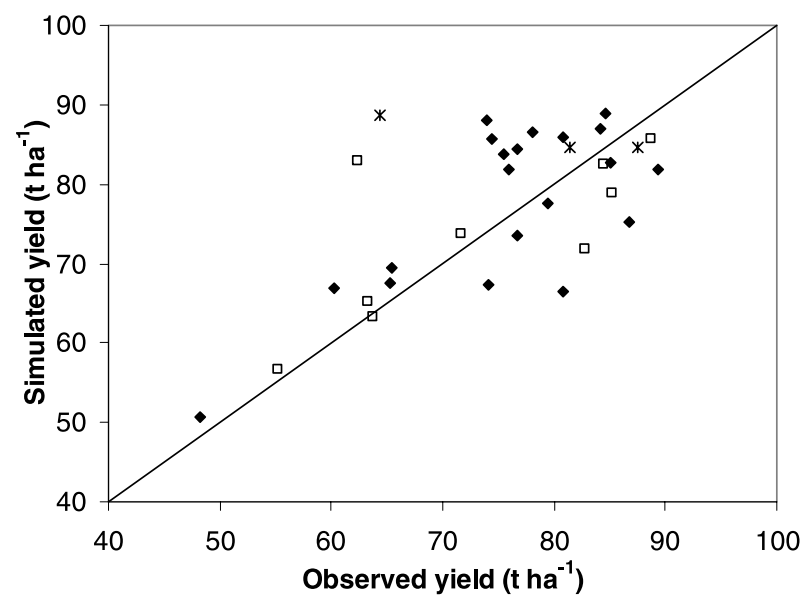

Figure 11. Yields simulated by the modified SUCROS model as a function of yields observed for the 20 plots with accurately detailed information on climate and soil type ( ), the 9 plots with accurate soil type data but inaccurate climate data $(\square)$, and the 3 plots with accurate climate data but inaccurate soil type data $(*)$.

\subsubsection{Performance of the model in the special case of plots on a chalk substratum}

The final group in our sample was made up of two plots, accurately detailed in terms of their weather and soil, but differing in the presence of chalky substratum. On one plot, $36 \%$ of the area was on a chalky substratum at a depth of $0.85 \mathrm{~m}$, while on the other $81 \%$ was on a chalky substratum at a depth of $0.3 \mathrm{~m}$. Chalk could be present in two forms:

- as hard material, unaffected by frost and not penetrable by roots;

- as soft material, cracked and penetrable by roots, which could also serve as a reservoir for soil water, mobilised through capillarity rise or by the direct penetration of roots, as in a loamy soil (Maucorps, personal communication).

These two forms, with widely differing hydrodynamic properties, are not differentiated on the soil map for the Aisne department. We therefore tested two descriptions of the chalk on two plots:

- either as an impenetrable substratum;

- or as a silt loam, reaching a depth of $1.8 \mathrm{~m}$.

Figure 12 shows the simulated yields on these two plots, based on each hypothesis. On the first plot, the simulated yield ranged from 62 to $65 \mathrm{t} / \mathrm{ha}$, depending on the chosen hypothesis, which was insufficient to correct the deviation from the measured yield. On the second plot, most of which was situated on a shallow chalky substratum, the simulated yield ranged from 53 to $82 \mathrm{t} / \mathrm{ha}$, depending on whether the moisture properties of the chalk were nil or identical to those of a deep silt loam, while the measured yield was $67 \mathrm{t} / \mathrm{ha}$. It therefore appears that on this plot, the water retention properties of the chalk were intermediate between those of a hard rock and deep soil.

Uncertainty about the climate and soil moisture properties, markedly degraded the performance of the model in terms of

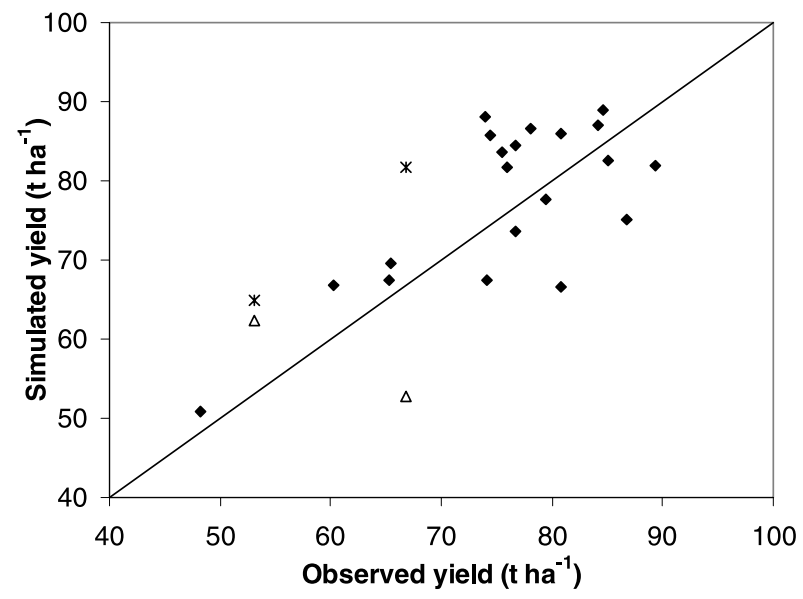

Figure 12. Yields simulated by the modified SUCROS model as a function of yields observed for the 20 plots with accurate climate and soil type data $(\bullet)$ and the two plots with accurate climate and soil type data but with more than $35 \%$ of their surface on a chalky substratum ( $\triangle$ in the case where chalk is considered to be a substratum, $*$ in the case where chalk is considered to be deep loam).

its ability to predict the yield on a plot scale within the sugar beet production region.

\section{DISCUSSION AND CONCLUSION}

\subsection{Model performance at regional scale}

Using average variables of crop growth obtained during experiments in two years, we modified the SUCROS model by introducing a variable which takes into account the effect of moisture stress on the leaf senescence rate and on the partitioning and translocation of assimilates between above-ground and storage organs. This relatively rough calibration of the model enabled SUCROS to better simulate LAI and sugar production. It allowed us to apply the model in the sugar beet-production regions in 1995, with reasonable confidence. However, we cannot claim this modifications to be of general value. A more robust calibration of the model will require the collection of much more data, obtained under contrasting cultivation and climatic conditions, with a measurement frequency much closer to that of variations in moisture stress. A more general study of the model is currently under way. Modifications to the SUCROS model made it possible to reduce errors of yield estimation and better reflect their variability.

\subsection{Error analysis}

1. The model's sensitivity to the accuracy of input variables was evaluated. To overcome the difficulty of quantifying the error on soil and weather description, we proposed criteria to identify those plots which were accurately characterised. The error of yield estimates increased by $13 \%$ when adding the inaccurately characterised plots to the accurately characterised ones. The soil description error was small, probably because the soil in this region is reasonably homogeneous. However, the chalky soils 
represent a particular case as their water retention properties may vary a lot spatially according to the pedogenesis. The weather description error was evaluated according to an arbitrary criterion depending on the distance between the plot and the weather station. An alternative approach would be to use in-plot weather measurements to analyse the likely effect of climate spatial uncertainty.

2. The error of yield estimates on accurately detailed plots could not only be explained by an irreducible structural error in the model [19], but also by a residual error in the estimation of other input variables or parameters which were assumed to be spatially constant. Among these variables or parameters, two were shown to be important in a sensitivity analysis [14], the maximum root depth, which we fixed hypothetically at $1.8 \mathrm{~m}$, and the root growth rate which we supposed to be $0.012 \mathrm{~m} /$ day, but which could vary spatially as a function of pedogenesis and of soil structure. Similarly, the water retention properties of chalk cannot be considered as uniform throughout the sugar beet producing region.

As a consequence, any gain on both soil and weather characterisation and on the determination of sensitive parameters in the model, would improve the model's ability to estimate yield variability. Methods have been developed which enable a spatial re-estimation of those variables and parameters. The assimilation of remote sensing data into crop models $[3,11,14]$ is one of these methods, upon which we base our hopes for a better characterisation of the spatial variability of crops and hence the better prediction of yields on an ever increasing scale.

Acknowledgements: We would like to thank Jean-François Savalle and Jean-Michel Chassine at Saint Louis Sucre, as well as all members of staff in the regional offices of the Institut Technique de la Betterave Industrielle for the Somme and Aisne departments, for their support during measurement campaigns. We would also like to thank Carolyne Durr for the data on sugarbeet emergence, Jean Maucorps for his advice and expertise on soil map interpretation, the Chambre d'Agriculture de l'Aisne who supplied the soil map, and particularly Michel Bernard for his expert assistance. Finally we thank Bertrand Ney for his helpfull comments on this paper. This programme received funding from the Picardy Region and the Institut Technique de la Betterave Industrielle.

\section{REFERENCES}

[1] Basso B., Ritchie J.T., Pierce F.J., Braga R.P., Jones J.W., Spatial validation of crop models for precision agriculture, Agric. Syst. 68 (2001) 97-112.

[2] Boiffin J., Durr C., Fleury A., Marin-Lafleche A., Maillet I., Analysis of the variability of sugar beet (Beta vulgaris L.) growth during the early stages. I. Influence of various conditions of crop establishment, Agronomie 12 (1992) 515-525.

[3] Bouman B., Goudriaan J., Linking crop models and remote sensing data, Proceedings 1st Congress E.S.A., Paris (France), 1990.

[4] Brouwer R., Some aspects of the equilibrium between overground and underground plant parts, Jaarb. IBS (1963) 31-39.

[5] Ceotto E., Guérif M., Duke C.L., Evaluation of the model SUCROS2 for simulating sugar beet growth and production in water limited conditions in Northern France, in: Proceedings of ESA International Symposium "Modelling Cropping Systems", Lleida (Spain), 1999.

[6] Clover G.R.G., Smith H.G., Azam-Ali S.N., Jaggard K.W., The effects of drought on sugar beet growth in isolation and in combination with beet yellows virus infection, J. Agric. Sci. 133 (1999) 251-261.

[7] Damay N., Le Gouis J., Radiation use efficiency of sugar beet in Northern France, Eur. J. Agron. 2 (1993) 179-184.

[8] Durr C., Boiffin J., Sugarbeet seedling growth from germination to the first leaf stage, J. Agric. Sci. 124 (1995) 427-435.

[9] Durr C., Guérif M., Brochery F., Ferré F., Study of crop establishment effects on subsequent growth using a crop growth model (SUCROS), in: Proceedings of ESA International Symposium "Modelling Cropping Systems", Lleida (Spain), 1999.

[10] Ferré F., Fleury A., Structure du peuplement, développement du couvert foliaire et efficience d'interception, in: Boiffin J., Choppin de Janvry E. (Eds.), Implantation de la betterave industrielle, Les colloques de l'INRA, 67, 1994, pp. 113-141.

[11] Guérif M., Duke C.L., Calibration of the SUCROS emergence and early growth module for sugarbeet using optical remote sensing data assimilation, Eur. J. Agron. 9 (1998) 127-136.

[12] Guérif M., Machet J.M., Droulin J.F., Utilisation de la télédétection pour caractériser le statut azoté des cultures de betteraves sucrières, in: Proceedings of the 58th IIRB Congress, Beaune (France), 1995, pp. 551-556.

[13] Jaggard K.W., Dewar A.M., Pidgeon J.D., The relative effects of drought stress and virus yellows on the yield of sugarbeet in the UK, 1980-95, J. Agric. Sci. 130 (1998) 337-343.

[14] Launay M., Diagnostic et prévision de l'état des cultures à l'échelle régionale : couplage entre modèle de croissance et télédétection. Application à la betterave sucrière en Picardie, $\mathrm{Ph} . \mathrm{D}$. thesis, Institut National Agronomique Paris-Grignon, $72 \mathrm{p}$.

[15] Mayer D.G., Butler D.G., Statistical and graphical validation, Ecol. Model. 68 (1993) 21-32.

[16] Meynard J.M., David G., Diagnostic sur l'élaboration du rendement des cultures, in: Fertilité des sols et nutrition des plantes, Sorrento Symposium, Italie, 1987.

[17] Milford G.F.J., Pocock T.O., Riley J., An analysis of leaf growth in sugar beet. II. Leaf appearance in field crops, Ann. Appl. Biol. 106 (1985) 173-185.

[18] Milford G.F.J., Travis K.Z., Pocock T.O., Jaggard K.W., Day W., Growth and dry-matter partitioning in sugar beet, J. Agric. Sci. 110 (1988) 301-308.

[19] Passioura J.B., Simulation Models: Snake Oil, Education, or Engineering?, Agron. J. 88 (1996) 690-694.

[20] Scott R.K., Jaggard K.W., An analysis of the efficiency of the sugar beet crop in exploiting the environment, in: Biennal Meeting of the American Society of Sugar Beet Technologists, Anaheim, USA, 1993, pp. 37-56.

[21] Sebillotte M., Système de culture, un concept opératoire pour les agronomes, in: Le point sur...Les systèmes de culture, INRA éditions, Paris, 1990, pp. 165-196.

[22] Smit A.B., Struik P.C., The first step towards a decision-support system for sugar-beet growing: selection of a basic growth model, J. Agron. Crop Sci. 175 (1995) 213-220.

[23] Spitters C.J.T., Van Keulen H., Van Kraalingen D.W.G., A simple and universal crop growth simulator: SUCROS87, in: Simulation and system management in crop protection, in: Rabbinge R., Ward S.A., Van Laar H.H. (Eds.), Simulation Monographs, Purdoc, Wageningen, 1989, pp. 147-181.

[24] Vandendriessche J., Van Ittersum M.K., Crop models and decision support systems for yield forecasting and management of the sugar beet crop, Eur. J. Agron. 4 (1995) 269-279.

[25] Van Laar H.H., Goudriaan J., Van Keulen H., Simulation of crop growth for potential and water-limited production situations (as applied to spring wheat), Simulation Reports CABO-TT 27, 1992, $71 \mathrm{p}$.

[26] Werker A.R., Jaggard K.W., Allison M.F., Modelling partitionning between structure and storage in sugar beet: Effects of drought and soil nitrogen, Plant and Soil 207 (1999) 97-106. 